\title{
Schooling for Work in New Zealand: Reproduction, Contestation and Transformation in three High Schools
}

\author{
Ronald G. Sultana \\ University of Malta
}

\begin{abstract}
This study records messages given to students about work within three high schools in New Zealand. Attention was given to overt and covert messages, and to those messages embedded in the structure of schooling itself. The study contributes to the debate within the 'new'sociology of education in that it focuses on the relationship between schooling and the established order in society. The data collected show that generally, the form, content and pedagogy of schooling function to serve the needs of industry rather than those of democracy. While teachers are described as functioning in the reproductive mode, the contradictions and conflicts observed are highlighted to show that reproduction does not take place without contestation. This opens up spaces wherein students and teachers can exercise agency and autonomy to question - and formulate alternatives to - the structure.
\end{abstract}

\section{Introduction}

This study draws on data from a research project which set out to discover and critically analyse the messages about work and non-work given overtly and covertly by three high schools in a provincial city of the North Island of New Zealand. The data collected throughout 1986 was used in a doctoral dissertation entitled 'Schooling for Work in New Zealand: A Qualitative Study of Three High Schools' (Sultana, 1987) In this overview of that research, the messages given within the three schools are placed within a theoretical context, with special attention being paid not only to the transmission process - with its reproductive and transformative dimensions - but also to the active reception, modification and contestation of these messages on the part of students.

\section{The Schools}

The three schools involved in this study are referred to here under the pseudonyms of 'All Girls' High', 'Co-Ed High' and 'All Boys' College' to indicate the nature of their student population, and were purposely chosen to represent different and contrasting educational climates. It was posited that this choice would maximise the possibility of the exposition of schools as sites of struggle over meaning, and that 'the common-sense values and beliefs that guide and structure educational practice are not a priori universals, but social constructions based on specific normative and political assumptions' (Giroux, 1982).

Two of the schools, All Girls' High and Co-Ed High, were large state schools catering for most if not all the city's ethnic (mainly European, Maori, Pacific Island and 
Asian) and social class groups. The former school had a particularly developed understanding of feminist issues, while the latter led the region in its attempts to develop a multicultural approach to education. Both these initiatives will be considered at greater length in another section of this article. Other aspects of the ethos prevalent at All Girls' High were a strict sense of discipline, an emphasis on competition, and the promoting of an 'elite' culture which would distinguish this particular school from all the other schools in the region. Co-Ed High prided itself on being the most 'progressive' school in the city: it was the only school where uniforms were not worn, where corporal punishment was no longer practised, and where relationships between students and teachers were relaxed, with the former often addressing the latter on a first-name basis.

All Boys' College differed from the other two schools in various ways: it was an integrated $^{1}$ Catholic school catering for predominantly Pakeha (European) and middle-class males. It was also the smallest school in the sample, having a population of 450 compared to the 950 for the girls' school and 1400 for the co-educational one. Staff-student relationships at the College were rigidly hierarchical, with emphasis being placed on discipline, hard work, and excellence in academic endeavours and sports.

\section{Theoretical Context}

The perspective adopted in this study relates schooling to a wider, fundamental context, namely the economic structure of society. The organisation of production, the division of labour and levels of technology are seen to establish the macro-context of schooling, and the social relations - of class, gender and ethnicity — which characterise the present social order are considered to structure the processes of formal education. The beliefs and practices of the teachers (as givers of messages) and students (who receive, accept and/or contest these messages) are in themselves a crucial aspect of the school's contribution to the social order. Class, gender and ethnic relations in New Zealand, and how these are developed generally, and within the family, the neighbourhood, and the school in particular, are considered to establish the limits and constraints of social, political and intellectual life in general. Such a view therefore links this study with other neo-Marxist and culturalist accounts of education. ${ }^{2}$

From this perspective too, all social relations of class, gender and ethnicity are considered to be relations of domination and subordination, with some groups benefitting more than others from the same social-economic organisation. As Jones (1986, p.75) has pointed out for the New Zealand context:

'In broad terms, dominant class, race and gender groups are enabled to control or influence in their own interests almost the entire matrix of institutions which constitute New Zealand society, including the definition and distribution of material, wealth, goods, services and socially valued knowledge, while the collective interests of subordinate groups are not met in the prevailing social and economic organisation'

The research was also guided by a specific epistemological approach. In this regard, it is useful to consider Bernstein's (1976) synthesis of twentieth century philosophical forces dialectically at work in the shaping and challenging of our views of what constitutes social science, and his injunction that good social and political theory must at one and the same time be empirical (grounded in data), interpretive (dealing with human subjective and inter-subjective meaning) and normative-critical (bringing ideologies to conscious awareness and make action-value decisions).

In this particular study, the researcher follows the concerns of theorists like Marcuse and Habermas who see pure positivism as an ideology focusing our inquiries and lives 
on the technical, and on finding effective means to get us to educational ends that we take for granted - ends that preserve the status quo and the power of the dominant class without regard for what kind of social and human life our current forms of schooling produce and reproduce.

In sharing Habemas' and Marcuse's rejection of positivism the researcher sought to demystify educational institutions and practices. Following Giroux (1983) and others within the tradition of the Frank furt school, the researcher therefore rejected the myth of value-free research into educational phenomena, and accordingly stressed the need for an inquiry that took into account the contemporary historical-ideological moment - in this case, a severe crisis in capital accumulation - and the influence this had on others. The link with interpretative inquiry in this particular research is the interest in human intersubjective meaning so that an understanding can be reached as to how education initiates students into a particular understanding of work.

\section{Methodology}

A research strategy which generates qualitative data, situates the latter within a wider context, and accepts the epistemological stance of normative inquiry, is provided by Grounded Theory methodology. This was pioneered by Glaser and Strauss (1967) and used in the study of New Zealand education by Battersby (1981)and Ramsay et al. (1983) among others. The methodology enhances the generation of formal and substantive propositions 'grounded' in qualitative data. In this particular study, information collected was organised according to categories, and propositions were formulated which could explain the data. Extensive efforts were then made to 'saturate' the propositions with data, to either confirm, modify or challenge the emerging theory. For the propositions to become part of theory, they had to be substantiated by similar data which occurred frequently in the field. Thus, any excerpts included in the final report - and in this paper - are not 'anecdotal' but are typical of others gathered throughout 1986.

In the recording of messages about work communicated at school, four steps were followed. The researcher first set out to establish the kinds of messages teachers and schools wanted to give to students. These were their 'intended messages'. Lessons, units, programmes and informal interactions between teachers and students were then observed by the researcher, and the data recorded during these sessions constituted 'actual messages'. Students were then interviewed in order to establish which messages were actually received, and which were accepted and/or contested. Finally, the differences between the intended, actual and received messages were communicated to teachers individually and in groups in order to set into motion the action phase of the research. This sequence has been pioneered by Osborne and his colleagues (1982) in their Learning in Science Project.

Extensive attention was paid to the official discourse as evident in syllabi, schemes of work, textbooks, and school publications. Many of the intended messages were embedded in such texts. Unstructured interviews were the second major source of data, and these were recorded, transcribed and analysed so that themes and categories could be identified, and questions formulated for the more structured interview schedules used in the second phase of the research.

182 out of a total of 197 school days were spent in carrying out observations in the field: the latter included observations and interviews carried out in the staffrooms, in the classrooms, at assemblies, parents' evenings, school camps, work exploration placements, and recreation programmes. In all, 151 lessons were observed. These 
included careers and transition education programmes, social studies, English, economics and history lessons, as well as classes in secretarial studies. Each of these lessons was generally of an hours duration.

370 students were interviewed individually and in groups of up to five. 187 of these students were female. 87 identified themselves as Maori, and of these 49 were female. 50 teachers were interviewed individually and 23 of these were female. Three were teachers of Maori language and culture, and two of these were female. Most interviews lasted one hour.

Despite the extent of the research, the data remain qualitative and apply specifically to the three schools in question. Qualitative research therefore can at best claim to provide people involved in similar circumstances with material which may be of some use to them in sharpening their own perceptions and procedures, rather than to produce some set of 'universal truths'.

\section{Findings}

The summary of findings draws together some of the major themes explored in the longer study and organises them in such a way as to highlight the function of schooling in reproducing the social order by responding to the industrial impulse, and in transforming it by responding to the democratic impulse. The terms 'industrial' and 'democratic' are considered to be in opposition to each other, and refer specifically to the kind of dialectic explored by Carnoy and Levin (1985). The latter authors build on Bowles' and Gintis' (1976) correspondence principle to suggest that the relationship between education and paid work is dialectical, characterised by a perpetual tension between two dynamics: the imperatives of capitalism and of democracy. Thus, schools respond to the needs of the capitalist workplace and to the values and expectations associated with the democratic rights of citizens.

This dichotomy is not to be represented in a simplistic fashion, for it is obvious that the generation of wealth depends on the development of the forces of production. What is at issue here is the context in which such development takes place: in other words, what kinds of social relations does industrial 'development' generate, and who stands to gain and to lose from such 'development'? Gintis (1980, p.193) articulates this dichotomy by distinguishing between 'property rights' and 'person rights' in the following manner:

A property right vests in individuals the power to enter into social relationships on the basis and extent of their property. This may include economic rights of unrestricted use, free contract, and voluntary exchange; political rights of participation and influence; and cultural rights of access to the social means for the transmission of knowledge and the reproduction and transformation of consciousness. A person right vests in individuals the power to enter into these social relationships on the basis of simple membership in the social collectivity. Thus, person rights involve equal treatment of citizens, freedom of expression and movement, equal access to participation and decision-making in social institutions, and reciprocity in relations of power and authority.

Carnoy and Levin (1985) argue that in any historical point in time, there is a tendency for one aspect of the duality to gain primacy at the expense of the other. This may happen simultaneously in a variety of social sites, including schools. They argue that when social movements are weak and business ideology strong, schools tend to strengthen their function of preparing and socialising students for paid work. These authors reiterate a point made by a number of scholars - including Apple (1982) - that the 
discourse of business has gained currency in the United States, and that the social and educational thrust of the 1950 s and 1960 s towards equality and other democratic ideals has lost favour in comparison to what Apple (1986) refers to as the 'high-tech' solution to the crisis.

A number of countries experiencing a crisis in capital accumulation have witnessed the swing towards 'property rights' with the consequent re-assertion of the industrial agenda in social institutions, including education. In the British context, a number of sophisticated analyses have been developed to account for this 'new vocationalism' by, interalia, Bates et al. (1984) and Dale (1985). Similar analyses have been carried out in New Zealand by Nash (1984) and Korndorffer (1987). The present research is located within the same tradition, and in subsequent sections of this paper the response to the industrial and democratic impulses on the part of schools and teachers is considered.

Most of the analyses cited inthe paragraphs above are mainly concerned with the ideological transmissions made by formal educational and training establishments. The original contribution of this study is the systematic emphasis which is also placed on the reception of these transmissions on the part of students. Through ethnographic excerpts it will be made clear throughout that students react to the messages they receive, actively producing - not just reproducing - meaning. As Gramsci (1971, p.35) noted, learners are active beings, capable of refashioning knowledge according to their individual consciousness which reflects the social and cultural relations to which they are exposed.

\section{The givers of messages and the ind ustrial impulse}

Certainly by far the vast majority of teachers observed in the three schools in this study were reproductive - in intent and in effect. It would therefore be true to say that generally, and with regards to school-to-work messages in particular, the most pervasive theme to emerge from the study was that through knowledge forms, knowledge content, and classroom social relations schools and teachers represented the ind ustrial rather than democratic - imperative. Schools and teachers were found to inculcate those qualities appreciated by employers, and specifically those qualities functional to an economy in crisis. With varying degrees of emphasis among the three schools studied, the social relations developed were authoritatively hierarchical and promoted passivity, docility and silence. They generally followed a 'banking' approach to education, establishing the teacher as the expert and dispenser of knowledge, and failed to appreciate the different experiences of students.

It is significant to note the correspondence between the process of work and the role of workers - themselves the educational topic - and the process of study and the role of students. The latter were thus generally involved in tasks which only had an extrinsic validity, so that just as people work hard in order to live, so did students learn in order to clinch a job. Like workers too, students were rarely observed being encouraged to participate actively, creatively and critically in the work/learning process. As Jensen (1986) notes in his analysis of similar work education programmes in Denmark, knowledge consumption rather than production was encouraged, so that:Simon's (1983) observation that teachers teach for rather than about work applied to the present study as well. Fifth formers from All Girls' High noted that

'Teachers kind of tame you . . . to put up with so much boredom!. . You're taught to be disciplined and listen, otherwise you get into serious trouble. . . If you take somebody who hasn't been to school all her life, and at eighteen she tries to enter a 


\section{Ronald G. Sultana}

job, she'll be a rebel!'

(Fieldnotes, 24/7/86, pp.1011-2)

Often therefore, relationships fostered in the classroom failed to encourage students to mutually appreciate each other, or to understand and express themselves through their work. This often resulted in an ethos of competition between students and of passivity in front of authority, and produced an ideology inasmuch as it provided an effective guide to social practice within capitalist society. As fifth formers from All Girls' High noted, ' . . you have tests right from the word go, and it's always like that: if somebody's going to be at the top, somebody else has got to be at the bottom' (Fieldnotes, 18/3/86, p.441).

Most of the ideas communicated by teachers about work were idealised, with work presented either as a self-fulfilling activity (with examples drawn from the professional careers) or as drudgery (factory work). Teachers generally avoided controversial issues such as the role of trade unions (see Sultana, 1 188 ? the problems of workers arising from their age, class, gender and/or ethnicity. For the vast majority of students 'unions are like a secret ... you only learn about them when you leave school' (Fieldnotes, 20/8/86, p.1167).

Overt messages were overwhelmingly of the type that urged students to fit into and perform in the world of work as it existed, rather than explore its nature. Generally speaking, the organisation of the forces of production was presented in an a-historical, reified manner, with employers being promoted uncritically as rightfully placed in positions of power deserving not only the surplus value of workers' labour, but also the latters' respect, obedience and co-operation. Co-Ed High fourth formers noted for instance that their social studies teacher urged them 'just mainly to please employers. In class they just tell you what the employers want. . . It's sort of employers are up top and workers way down bottom, as if employers are more important than workers' (Fieldnotes, 29/9/86, p.1324).

Both covertly - through the inculcation of a competitive ethos and values of abdication and self-denial - and overtly students were taught to put the employer's needs above their own, or seeing them as complementary rather than conflicting. Workers were generally presented as involving themselves in competition for better places in the social order, rather than voicing a unified concern for their own rights and dignity. As a CoEd social studies teacher admitted regarding the selective tradition of the curriculum he was imparting, 'Students are not given any pictures of employers' exploitation of workers' (Fieldnotes, 24/7/86, p.1004).

The hierarchical arrangement of labour was presented as 'common sense', as were the differential status and rewards afforded to different workers. Students were therefore to take their place in this occupational ladder, but little or no light was shed on the influence of class, ethnicity (see Sultana, 1988b), and gender in determining specific locations on the ladder, and the results of that location for their future lives. Rather, teachers often participated in defining the 'realistic' and the 'appropriate' for particular students. The following classroom interaction in a transition-to-work programme attended largely by working class youth is a case in point:

Stephen: I want to be a cook miss.

Ms Bowie: I'll try to find you work in a coffee lounge.

Stephen: I want to be a cook, not a bleedin' coffee lounge waiter!

Ms Bowie: Right! I'll talk to you when you're in a better mood.

(Fieldnotes, 24/3/86, p.496) 
The only explanations offered to individuals for their reduced life-chances and lower positions in the wider social structures was that they had not striven hard enough to deserve better. Personal responsibility for system-caused injustice was therefore encouraged by an unproblematic promotion of certification, despite students' first hand knowledge that 'in these times it's who you know, not what you know' which clinched jobs (see Sultana, 1989c). Unemployment as a subject, and therefore the crisis in capital accumulation generally, was either not referred to at all, or else 'explained' in commonsensical ways: people were unemployed because they did not want to look for a job or because they did not have the 'skills' (to sit interviews, write their curriculum vitae and generally present themselves appropriately) to look for one. Otherwise, teachers evoked the ever present but ever mysterious 'recession'. There were certainly no attempts made to situate contemporary economic situations within a historical perspective where specific economic, political and ideological decisions were being made by people in power. Without an empowering education on such matters, students vaguely blamed, 'the government', 'trade unions', immigrant workers from the Pacific Islands, and 'computers and robots' for 'stealing jobs'. A fourth former noted that

'We're being taught to accept technology . . . that it's something that going to come. Teachers haven't said that there's an alternative. They're just kind of going along with it. Education . . . mainly . . . it's teaching us how to cope, I think?

(Fieldnotes, 25/9/86, p.1291)

Throughout the lessons observed within economics, the subject was presented as a science rather than as a value system. The topic of unemployment evoked responses similar to teaching for employment: teachers encouraged patience, perseverence and competitiveness in the job-search process. If this failed to secure employment, then young people were encouraged to 'enjoy leisure'. As a Co-Ed High transition teacher told the researcher: 'How to handle unemployment has to become very much part of what we are trying to do . . . what they can do, how they can manage their lives and their money . . . to keep themselves busy' (Fieldnotes, 5/11/86, p.1612).

The study also considered in detail the efforts of some teachers to cater for the needs of students disillusioned with mainstream schooling (see Sultana, 1989a). Here too, and with a greater degree of emphasis, the personal was divorced from the political in that transition education and work exploration encouraged the atmosphere of job expectation while managing the anxiety of being unemployed. These curricular initiatives served the mainstream by removing undesirable elements from the classroom, offering in exchange the promise of specific skills which would lead to a job. While occasionally these promises were kept, transition education was found to reinforce the peripheral positions of students from working class and ethnic minorities in school and in the labour market.

All in all, teachers believed that schooling and teaching represented 'neutral' processes. A frequent aside to the researcher was that in New Zealand schools there are 'three taboo subjects, namely religion, sex and politics'. Teachers' general a-political stance is caught in the following comment by a teacher from All Girls' High:

'I wouId be very wary not to get into the political . . . I'm very cagey. Perhaps I'm wary of sticking my neck out and then get a little flak back from, eh, via parents. I think we've got enough problems in life without getting any more'

(Fieldnotes, 18/11/86, p.1697) 


\section{Ronald G. Sultana}

\section{The givers of messages and the democratic impulse}

This account has thus far tended to minimise the substantial inter-and intra-school differences noted among the three schools, and has made no reference to the antihegemonic messages recorded. If research is to lead at all to the 'language of possibility' (Aronowitz and Giroux, 1985) which finds its expression in Gramsci's 'pessimism of the intellect and optimism of the will', these differences and struggles have to be given prominence, and their significance for both theorists and practitioners highlighted. Such struggles, even when ultimately defeated, point towards the possibility and necessity for alternative practice on the part of teachers.

The actual data in which this discussion is grounded show that the three schools studied formed a contested terrain (Edwards, 1979) where as institutions they did not merely participate in reproductive forms of education, but were at the very same moment engaged in transformative agendas. As Carnoy and Levin (1985, p.50) have argued,

'The educational system is not an instrument of the capitalist class. It is the product of conflict between the dominant and the dominated. It is an area of conflict over the production of knowledge, ideology, and employment, a place where social movements try to meet their needs and business attempts to reproduce its hegemony'.

'Schooling for Work in New Zealand' therefore did not merely capture the reproductive and hegemonic tenor of schooling, dominant though this theme was. It also highlighted the individual and collective attempts on the part of teachers to promote what has earlier been referred to as 'person rights'. Schools and teachers were found to have a certain degree of autonomy, an autonomy which was directed towards various democratic ends (and with the expressed contestation of other groups with theirinterests in society), so that groups of students - especially those identified by their ethnicity and gender - could find a voice in the schooling process and establish a space to tell their story in their own words. Individual and collective attempts were made by teachers to oppose bureaucratic control and institutional definitions of the 'legitimate' curriculum and pedagogy, striving to lessen the reproductive role of the schooling process by encouraging critical thinking and action among their students.

By their very choice of 'clientele' in terms of class, gender and ethnicity, the three schools were found to be making a statement about their transformative or reproductive goals. They also indicated their willingness to participate in the struggles within the state for civil liberties and democratic rights in all their forms. Such transformative action was found to be most effective when the same ideological critique was shared by a group of teachers - a critique expressed through the school ethos, structures and curricula and located within wider social movements. This was the case for both CoEd High and All Girls' High, where in both instances the majority of teachers were caught up in social movements - the former mainly regarding ethnic rights, the latter regarding feminist issues - which helped them articulate an ideological critique of both schooling and the wider social order.

With regards to All Boys' College, the four religious brothers on the staff were observed attempting to lead their lay, often conservative colleagues towards educational goals consonant with liberationism. Thus, while the College was the most clearly reproductive of the inequalities in the social order, in intention at least its vision of education drew sustenance from a set of religious and ethical values which emphasised the rights of the oppressed in society, and argued for a better a more equitable social system. A school document explicitly set out the following agenda: defuse competition, respect 
differences, foster cultural groups, find work for unemployed, provide experiences of success for each, educate to change society and not merely to fit into it, denounce and resist where necessary, highlight social injustices such as racism, provide media education, teach change agent skills (Special Character, n.d., p.13).

This concern with democratic issues spilled over into the set of messages each school gave about the world of work. All Girls' High was particularly well-organised in its efforts to politicise and conscientise its students regarding the state of women's oppression in the New Zealand labour market. Its highly developed feminist programme encouraged students to consider roles and occupations outside the traditionally female, ahd as a school was found to function consistently as a political site in the construction of feminist discourse and subjectivities. This agenda took the form of an extensive campaign under the heading of 'Girls Can do Anything', co-ordinating with regional efforts in the same direction made by the Department of Labour and, at the national level, with media advertising challenging conservative thinking about women (see Sultana, 1989a). This campaign transformed the school's material environment (through posters, exhibitions and murals), introduced work shop options for girls, and generally strove to address issues related specifically to women and work.

Similar though less thorough efforts were observed at Co-Ed High, where the major focus was in the promotion of multicultural sensitivity. Various curricular and other initiatives were observed at this school, and the expressed intention was to enhance the status and educational achievement of its Maori and Polynesian population. This school's endeavours were largely liberal in comparison to those at All Girls' High in that cultural issues were generally divorced from political ones. There was also more evidence of contestation and conflict around the agenda among staff and students alike. In spite of this, a number of teachers overtly confronted the job apartheid prevalent in New Zealand (Brosnan, 1986), and two Maori teachers at this school were very active in encouraging Maori students to consider a variety of high status, traditionally Pakeha jobs.

At All Boys' College, however, various factors came together to ensure that the reproductive function of schooling was played out to the utmost. Significantly, one of the reasons for this was the active role played by the Concerned Parents' Association - a 'new Right' pressure group - in ensuring that a conservative ethos and curriculum prevailed. The practice of the 'old tie networks', where, as one employer told the researcher, 'We Catholics take care of our own' (Fieldnotes, 20/3/86, p.486), and the fact that the chairperson of the school's Board of Governors was the foremost Catholic employer in the region and a power-broker in the community, ensured that a 'business ideology' prevailed with a vengeance at this school.

It is important to point out that in all three schools there was a lack of understanding and appreciation of subordination based on class. Very few teachers offered explanations of their own activity - as well as the ideological nature of the messages they gave about work - with reference to a theory about social class formation in New Zealand. Ramsay et al. (1983) make similar remarks about their sample of South Auckland teaching communities.

\section{Discussion}

A number of reasons can be advanced to explain the bias in schooling which ultimately favours the needs of capitalist industry. The mechanisms relating industrial demands to educational processes are hegemonic, depending on symbolic rather than physical violence (Bourdieu and Passeron, 1977). Teachers are considered to participate in exerting symbolic violence both consciously and unawaredly. The latter form of par- 


\section{Ronald G. Sultana}

ticipation is partly explained through their class location and unconscious allegiance to the bourgeoisie. Steven (1978) makes this point in his attempt to provide a class analysis of New Zealand. He locates teachers within the middle classes, and arguing that - depending on the advanced state of surplus value that is produced - teachers do not experience capitalism as an external force, and 'can take more surplus value with one hand than $\mid$ they $\mid$ surrender with the other. |Their| interests therefore move closer to those of the bourgeoisie' (p.124).

He also argues that slow accumulation of surplus value will test the loyalty of teachers to the dominant class, and enhance their proletarianisation. Teachers become increasingly critical of capitalism so that 'as the crisis deepens the bourgeoisie will find in the middle-class an increasingly unreliable ally, although not too much hope should be placed on this' (ibid., p.125). Despite the critical state of capital accumulation in New Zealand, and the way this is felt by teachers in terms of lower salaries, vulnerability of tenure and threats of accountability, there was little evidence in the data to show that they were openly critical of capitalism, and specifically so in the classroom.

Another reason to account for teachers' unconscious reproduction of the social order is their lack of political literacy. This sort of literacy is vital if, as Giroux and McLaren (1986, p.225) have argued, teachers are to move away from the dominant view of themselves as primarily technicians or public servants whose role is to implement rather than to conceptualise pedagogical practice. Hargreaves' (1984) comment that teachers have a 'culture of individualism' is applicable to many of the teachers in this study. The latter were characterised by a humanistic, child-centred and psychologistic conception of teaching and learning which rendered them blind to social phenomena in contrast to individual characteristics.

Thus, most of the teachers observed had little understanding of how their actions relate to the wider structure of society. Moreover, those who did appreciate this relationship were often noted to be constrained on the one hand by the larger school structure, and on the other hand by their lack of resources, personal and otherwise, to develop the kind of critical education and pedagogy which addresses democratic issues - in the world of work and elsewhere. It is therefore necessary to supplement a structuralistfunctionalist approach to understanding teachers' social class-located hegemonic activity by also getting accurate bearings on the social situations of teachers, the constraints they work under, and the possibilities open to them (Connell, 1985). A geography teacher, an active member of the peace movement who often presented radical perspectives on 'underdeveloped countries', commented sadly about how school structures forced him to jettison values, such as the sharing of authority with students: 'So you enter the structure and bang go your values, because how are you going to run a programme with twenty five different people?! The structures do violence on us as much as on the students!' (Fieldnotes, 7/11/86, p.1633).

An account of the conscious reasons to explain the teachers' emphasis on the needs of industry utilises Apple's (1978) argument of 'structural causation'. The conspiracy approach implicit in the work of the early Bowles and Gintis is therefore viewed critically in this context. The process of reproduction that schools are involved in, and the various structures developed to facilitate this (including transition education, work experience, and life skills teaching) is not the work of an 'elite group of managers . . plotting ways to "do in" their workers at both the work place and the school' (Apple, 1978, p.384). Rather, the existing patterns of productive relations among individuals and social groups will naturally generate actions that lend support to the allocation and socialisation of students into unequal productive relations. Apple (1978, p.385) argues: 
Given the extant economic and political forms which now provide the principles upon which so much of our everyday lives are organised, this reproductive process is a 'logical necessity' for the continued maintenance of an unequal social order. The economic and cultural imbalance follows 'naturally'.

In other words, what the teachers teach is what they think employers want - not necessarily because they 'believe in the values of advanced industrial capitalism, but because they believe that given the unequal outcomes of society, a student may face unemployment without these values' (Watkins, 1980, p.42). The emphasis on employability provides the basis for the reproduction of the social relations, the culture and the ideology of business in the classroom. What can be referred to as the job-getting imperative' achieves further prominence with teachers as jobs become more scarce. Thus, decisions made about what to teach had to do less with the ideals of justice and equality which teachers generally endorsed, and more with the practical concerns of achieving a livelihood. This was seen to operate even in the two areas where transformative education was most explicitly engaged in, namely gender and ethnicity.

This sort of tension is best expressed by the most progressive teacher observed in all three schools. She described her dilemma between choosing to teach her students to become critical, and teaching them to adapt. She mentioned the case of one student who had accepted many of her critical ideas, and who, on finding work,

‘. . was unable to tolerate the bullshit, and she chucked in the job. She's going to have real difficulties | finding work and| fitting into work structures which are going to say: "You must suppress yourself!" And so, it makes me nervous when I see that. . . It is not our job to produce a person who fits nicely into the conveyer belt, and yet, if they want to survive, they will have to fit.'

Fieldnotes, 3/10/86, p.1392)

This sort of dilemma to some extent explains the conflicts noted in teacher practice, conflicts which are exemplified by the following contradictions in teachers' messages and attitudes observed throughout the year:

- Skills and qualifications are needed more and more, but personal qualities are what employers are really looking for.

- School qualifications secure jobs, but qualifications are losing their strength.

- Unemployment is mentioned for control and motivation purposes, but is played down as a topic for fear of the loss of the legitimacy of schooling.

- The work ethic is no longer appropriate, but is at the same time reinforced by the insistence on the investment in certification as a 'salvation' from unemployment.

- Choice of occupation should be carefully made as this leads to fulfilment, but if everybody has these 'skills', the competitive edge is lost.

- Female (and Maori) students are not to be bound by stereotypes in their approach to the labour market, but it is best to choose 'traditional' jobs to ensure employment.

- Sexual and racial discrimination is bad, but you had better put up with it if you want to secure and keep a job.

In a similar context, Simon (1983, p.284) argues that the work of teaching embodies contradictory moments, and involves contradictions that cannot be resolved at an individual level since their origin is in the social order. The contradictory messages out- 
lined above are not the products of confused minds, but are rather the result of 'teachers' participation in sets of social relations which reflect conflicting interests and orientations' (Simon, 1983, p.249).

\section{Conclusion}

The research findings summarised in the preceding sections make a number of important points not only at the substantive level (i.e. the discovery of the school-to-work messages transmitted within three educational establishments), but also at the formal theoretical one. With regards to the latter dimension, schools - like other social sites - were found to have an internal cultural politics of their own, 'characterised by processes of conflict and contest, negotiation and exchange, resistance and accommodation' (Hogan, 1982, p.58).

This sensitivity to the complexity of social sites draws together the two strands in the Leftist tradition of educational scholarship. The first strand refers to an economic determinism which stresses the connections between educational institutions and economic power. In following this tradition, the three schools were seen to reproduce both labour power for the capitalist class and ideological consciousness which legitimates capitalist production and defends the status quo. Every aspect of schooling, therefore, whether it is its organisational structures, its particular ethos as expressed through rituals, or its curricular structure and discourse, was considered to define a mode for the production of ways of thinking that are fundamentally linked to specific interests within a concrete form of economic and social organisation.

The study also followed a second and more recent strand of social theory which has been influenced by a culturalist Marxism which considers cultural processes to be intimately connected with social relations (Willis, 1977). This connectedness is neither an autonomous nor an externally determined field, but a site of social differences and struggles (Dwyer et al., 1984). The study of the relationship between schooling and work, and of the specific school-to-work messages therefore highlighted the intricate relationships between macro-economic and social forces and the realities of teachers' - and students' - everyday lives. The ethnographic data - occasionally drawn upon in this paper - increases the possibility of doing justice to this complexity by exposing the internal life of schools so that processes of conflict, negotiation, resistance and accommodation can be identified, and the way meanings and messagers are forged can be revealed. By moving away from the idea of schools as a 'black box', such research alerts us to both the possibilities of spaces for transformation, and to the structural constraints within which this endeavour is bound.

\section{Notes}

* The research was funded by the Commonwealth Scholarships Association (New Zealand) in conjunction with the Department of Education of Malta.

** I would like to thank Associate Professor P.D.K. Ramsay and E.J. Wadsworth (University of Waikato, New Zealand) for responding to draft versions of this article.

1. In New Zealand, the Private Schools Conditional Integration Act of 1975 authorised the absorption of private schools into the state system, which meant that they could receive funding completely from the state. Integrated schools were to follow state school prescriptions and were to be subject to state school inspectors. Those 'integrated' were however allowed to keep their 'special character', which signifies an education within the framework of a particular or general religious or philosophical belief and associated with observances or traditions appropriate to that belief.

2. This finds its expression in the works of authors in the 'new' sociology of education and critical education tradition, chief among them being Young (1971), Apple (1979, 1982), Anyon (1981), Giroux (1983), 
and Whitty (1985). New Zealand exponents of this approach are Ramsay et al. (1983), Codd et al. (1985) and Jones (1986), among others.

\section{References}

Anyon, J. 'Social class and school knowledge', Curriculum Inquiry, Vol.11, No.1, pp.3-42, 1981.

Apple, M.W. 'Ideology, reproduction and educational reform', Comparative Education Review, Vol.22, No.3, pp.367-387, 1978.

Apple, M.W. Ideology and the Curriculum, London, Routledge \& Kegan Paul, 1979.

Apple, M.W. 'The other side of the hidden curriculum: Correspondence theories and the labour process, Interchange, Vol.11, No.3, 1981.

Apple, M.W. Education and Power, Boston, Routledge \& Kegan Paul, 1982.

Apple, M.W. 'Bringing the economy back into educational theory', Educational Theory, Vol.36, No.4, pp.403-415, 1986.

Aronowitz, S. and Giroux, H.A. Education under Siege, South Hadley, Mass., Bergin \& Garvey, 1985.

Bates, I. et al. Schooling for the Dole: The New Vocationalism, London, Macmillan, 1984.

Battersby, D. The First Year of Teaching, Unpublished D.Phil dissertation, University of Waikato, Hamilton, 1981.

Bernstein, R. The Restructuring of Social and Political Theory, London, Methuen, 1976.

Bourdieu, P. and Passeron, J.C. Reproduction in Education, Society and Culture, London, Sage, 1977.

Bowles, S. and Gintis, H. Schooling in Capitalist America, London, Routledge \& Kegan Paul, 1976.

Brosnan, P. Maori Occupational Segregation, Working Paper No.2, Industrial Relations Centre, Victoria University of Wellington, 1986.

Carnoy, M. and Levin, H.M. Schooling and Work in the Democratic State, Stanford, Ca., Stanford University Press, 1985.

Codd, J.A., Harker, R. and Nash, R. (Eds) Political Issues in New Zealand Education, Palmerston North, Dunmore Press, 1985.

Connell, R.W. Teachers' Work, Sydney, Allen \& Unwin, 1985.

Dale, R. (ed) Education, Training and Employment: Towards a New Vocationalism? London, Pergamon, 1985.

Dwyer, P.J., Wilson, B. and Woock, R. Confronting School Work, Sydney, Allen \& Unwin, 1984.

Edwards, R. Contested Terrain, Basic Books, 1979.

Giroux, H.A. 'Culture and rationality in the Frankfurt school of thought', Theory and Research in Education, Vol.9, No.4, pp.17-55, 1982.

Giroux, H.A. Theory and Resistance in Education, South Hadley, Mass., Bergin \& Garvey, 1983.

Giroux, H.A. and McLaren, P. 'Teacher education and the politics of engagement: The case for democratic schooling', Harvard Educational Review, Vol. 56, No.3, pp.213-238, 1986.

Glaser, B.G. and Strauss, A.L. The Discovery of Grounded Theory: Strategies for Qualitative Research, Chicago, Aldine, 1967.

Gramsci, A. Selections from the Prison Notebooks, Ed. and trans.: Q. Hoareand G. Nowell Smith, London, Lawrence \& Wishart, 1971.

Hargreaves, A. 'Experience counts, theory doesn't: How teachers talk about their work', sociology of Education, Vol.57, pp.244-235, 1984.

Hogan, D. 'Education and class formation: The peculiarities of the Americans', In M.W. Apple (ed.) Cultural and Economic Reproduction in Education, London, Routledge \& Kegan Paul, pp.32-78, 1982.

Jones, A. At School I've Got a Chance: Social Reproduction in a New Zealand Secondary School. Unpublished D.Phil dissertation, University of Auckland, 1986.

Korndorffer, W. (Ed.) Transition: Perspectives on School-to-Work in New Zealand, Palmerston North, Dunmore Press, 1987.

Nash, R. Schools Can't Make Jobs, Palmerston North, Dunmore Press, 1984.

Osborne, R., Freyberg, P. and Tasker, R. The Research Appendix: Working papers on Methodology, Learning in Science Project, University of Waikato, Hamilton, 1982.

Ramsay, P.D.K., Sneddon, D., Grenfell, J. and Ford, I., 'Successful and Unsuccessful Schools: A Study in Southern Auckland', Australian and New Zealand Journal of Sociology, Vol.19, No.2, pp.217-234, 1983. 
Simon, R.I. 'But who will let you do it? Counter-hegemonic possibilities for work education', Journal of Education, Vol.165, No.3, pp.235-256, 1983.

Steven, R. 'Towards a class analysis of New Zealand', Australia and New Zealand Journal of Sociology, Vol.14, No.2, pp.113-129, 1978.

Sultana, R.G. Schooling for Work in New Zealand: A Qualitative Study of Three High Schools. Unpublished D.Phil dissertation, University of Waikato, 1987.

Sultana, R.G. 'Schooling tomorrow's worker: Trade union education in secondary schools', New Zealand Journal of Industrial Studies, Vol.13, pp.3-20, 1988a.

Sultana, R.G. 'Ethnicity and the reproduction of labour market locations: Do Maori students really have a choice?' Delta, Vol.40 (May), pp.51-68, 1988 b.

Sultana, R.G. 'Transition education, student contestation and the production of meaning: Possibilities and limitations of resistance theories', British Journal of Sociology of Education, Vol.10, No.3, pp.287-309, 1989a.

Sultana, R.G. 'Gender, schooling and transformation: Evaluating liberal feminist action in education', New Zealand Journal of Educational Studies, 1989b, (in press).

Sultana, R.G. '“It's who you know, not what you know": Penetrating the credentialling ideology', British Journal of Guidance and Counselling, $1989 \mathrm{c}$, (in press).

Watkins, P.E. 'Curriculum change and the school-work interface: A critical analysis of work experience', Australia and New Zealand Journal of Sociology, Vol.16, No.2, pp.37-44, 1980.

Whitty, G. Sociology and School Knowledge, London, Methuen, 1985.

Willis, P. Learning to Labour, Farnborough, Saxon House, 1977.

Young, M.F.D. (Ed.) Knowledge and Control: New Directions in the Sociology of Education, London, Collier-Macmillan, 1971. 